\title{
An Approach to Vulnerabilities, Threats and Risk in Voting Systems for Popular Elections in Latin America
}

\author{
Segundo Moisés Toapanta Toapanta*1 ${ }^{*}$ Iván Fernando Marriott Saá ${ }^{1}$, Félix Gustavo Mendoza Quimi ${ }^{1}$, Luis Enrique Mafla Gallegos ${ }^{2}$ \\ ${ }^{1}$ Department Computer Science, Universidad Politécnica Salesiana (UPS), Guayaquil, Ecuador \\ ${ }^{2}$ Faculty of Engineering Systems, Escuela Politécnica Nacional del Ecuador (EPN), Quito, Ecuador
}

\begin{tabular}{l} 
A R T I C L E I N F O \\
\hline Article history: \\
Received: 28 March, 2019 \\
Accepted: 17 May, 2019 \\
Online: 24 May, 2019
\end{tabular}

Keywords:

Elections

Latin America

Voting

E-Voting

\begin{abstract}
A B S T R A C T
The problems in information security regarding vulnerabilities, threats and risks in voting systems for popular election in Latin America and the world persist; because in most of the countries of the world there is no maturity in democracy and defined policies; the problems of confidentiality, integrity and authenticity in the electoral processes can be evidenced. The objective is to perform the analysis to identify the threats, risks and weaknesses in electoral systems in Latin American countries and determine which of the systems used by different countries may be appropriate, to be considered as an alternative. The deductive method and exploratory research has been used to perform the analysis of the articles and information regarding electoral processes. It resulted in a description in statistical tables of the threats and weaknesses that must be examined to implement a system for electoral voting; considering the culture, technological availability and social conditions of each country. It was concluded that to mitigate the potential risks of the information, it is necessary to identify the weaknesses in the electronic voting system to improve the integrity and security of the electoral process; made in the last three presidential elections in Brazil, Colombia, Ecuador.
\end{abstract}

\section{Introduction}

Numerous countries from Latin America incorporate several referendum systems for political elections. When exposed to the different cultures of countries, they can pose several risks and threats to the voting process.

Since the 90's, Latin America commenced a slow but steady process of adapting to new technologies and making use of them to enter the trend of adopting E-Voting. In 1996 and 1998 respectively, Brazil and Venezuela were the first nation to interact with this new system [1].

The desire involved with enforcing automation in voting systems is to optimize this process as well as the distribution of the outcome [2]. It aims an optimal way to try to minimize the election time as well as the waiting period of the outcome as much as possible. This has as a sole goal supplying security while decreasing the potential for election tampering at the polls and providing fairness and integrity to the electoral process.

*Segundo Moisés Toapanta Toapanta, \& Email: stoapanta@ups.edu.ec www.astesj.com
Some voting system processes require massive data handling and processing. Therefore the implementation of computerized procedures has obtained a significant advantage in terms of speed, security, and integrity [3].

Although not all countries in Latin America force or punish people who do not wish to exercise their right to vote, all citizens should be aware of the value of their vote in a democratic system. If they do not show concern for the person who will govern their country, it will be easier for them to be victims of abuse of power.

Why is it essential to perform an analysis in Latin America electoral systems in order to have free and fair elections?

Currently, the voting systems used presents different vulnerabilities, threats, and inherent risks. If not counteracted, these will have a serious negative impact on the voting process.

This research is organized as follows. In the second section, the materials and methods are showed. In the third section, the findings of the research are exposed. In the fourth section, the 
results are inspected. Based on these discussions future work is discussed in the fifth section. Finally, in the sixth section the conclusions of this research are presented, as well as some final remarks.

The ultimate goal of this research is to deliver an analysis focused on the distinctive properties in election systems introduced in Latin American countries. Furthermore, determine which of these systems is the most appropriate to be regarded as an efficient and viable alternative.

The deductive method is used to evaluate relevant information from articles pertaining to this research. The articles and books reviewed in relation to the subject are summarized in the Appendix.

The results reached are as follows:

1. A diagram that lists the qualities which are directly linked to non-functional and functional requirements.

2. A diagram showing the inherent vulnerabilities of the different type of voting systems, also caused by levels of malfeasance, fraud, and electronic illiteracy.

3. A table that identifies the various levels of criticality divided by a color code and a complementary table which summarizes the different risks that negatively impacts the voting systems.

4. Based on the historical information of the last three elections in Brazil, Colombia and Ecuador, data have been compiled and tabulated in tables that allow us to analyze the reality of the electoral processes that are being carried out at present.

It is finally concluded that once the weaknesses in Voting Systems have been alleviated and/or eradicated, from an objective perspective, E-Voting becomes the least risky and most efficient to incorporate in Latin America.

\section{Materials and Methods}

\subsection{Materials}

Latin America is made up of a large number of countries. For this study are taken into account those who can cover the greatest differences between populations, area, and implemented voting system as seen in Table 1, being these: Brazil, Colombia and Ecuador.

Brazil is one of the largest countries with the biggest population in Latin America and one of the pioneers in successfully migrating from traditional elections to electronic voting. Brazil has streamline the voting process and instituting the electronic voting system as the one used throughout the country since 1996 [4]. There are many countries that have decided to implement some registered pilot systems such as the case of Ecuador, which in 2004 decided to carry out E-Voting tests in some of its provinces, resulting in the country deciding to use the automated paper-based voting; contrary to Colombia, despite being one of the pioneers in 1992 when conducting an E-Voting pilot, has steadfastly refused to change keeping the traditional voting system [5].

Table 1: Differences between the Latin America representative countries.

\begin{tabular}{|c|c|c|c|}
\hline Country & Population & Area & Voting System \\
\hline Brazil & 208494900 & $\begin{array}{c}8,516 \\
\text { millions km² }\end{array}$ & $\begin{array}{c}\text { Direct-recording } \\
\text { Electronic }\end{array}$ \\
\hline Colombia & 49292000 & $\begin{array}{c}1.142 \\
\text { millions km² }\end{array}$ & Voting Ballot \\
\hline Ecuador & 17096789 & $283,560 \mathrm{~km}^{2}$ & $\begin{array}{c}\text { Automated paper- } \\
\text { based voting }\end{array}$ \\
\hline
\end{tabular}

There are several types of popular vote electoral system but those used in the selected Latin American countries can be classified mainly into two types.

\section{- $\quad$ Voting ballot system}

Many countries in Latin America use the ballot system referred from now on as a traditional election. Ballot system gives to their citizens the opportunity to be part of the selection of the political entity that will represent their country [6]. In the traditional election system, the regulatory authorities are responsible for providing voters with ballots and ballot boxes so they can exercise their right to cast a ballot. Consequently, the counting of the votes is carried out manually. Nevertheless, to announce the results, it must be taken into account that the winning candidate must win the absolute majority of valid votes that is more than $50 \%$ of the voters. If none of the voters exceeds this expectation, the election process must be repeated.

As a result, elections are made using a ballot and an urn. This particular system needs the direct involvement of a vast number of individuals belonging to a community that in the overwhelming majority of situations were not properly trained.

\section{- Electronic Voting System}

This type of system is also known as E-Voting. It was used for the first time in Latin America for the elections of president, state governors and legislators in 2000 in Brazil. Since 1996, different municipalities of the country started with the installation of electronic ballot boxes.

This has various mechanisms that store the votes where the elector or civil society entities can verify the security and the perfect functioning of the system. It depends exclusively on the reliability of the software used by the device, so the use of this system has been extended to Argentina and Mexico where the corresponding pilot tests have been carried out using the same technology [7].

The E-Voting electoral system has been divided into three different categories:

\section{Automated paper-based voting}

Among the three categories in which the E-Voting voting system has been divided, the automated reading of paper-based 
voting is the most inaccurate since both voting and counting are done by hand as in traditional elections. The information collected is transferred to paper and with special characters that are processable. Each of the results of the count is entered into machines designed specifically for the processing of this data, which can take between days and weeks.

\section{Direct recording electronic electoral system (DRE)}

In this type of voting systems, machines created specifically for this purpose are required, also known as electronic ballot boxes. They function in a similar way than a computer since the voting is done manually, but the machine offers simplicity in voting through either touch screens or buttons for selection. After the elections, the stored data are exported by means of some removable memory device and/or with a printed copy so that the voter and the entities belonging to civil society can check the security and integrity of the vote.

\section{DRE on public network}

The implementation of various technological advances has allowed some countries to opt for the use of a public network to offer citizens a more effective way to get involved in the voting process. Once the voting is done, the data will be encrypted to avoid manipulation by external agents. Then they can be broadcasted as individual results or as a final batch at the end of the elections. The computer will provide the results.

According to $[3,8,9]$ any of the electoral systems, whether traditional or E-Voting must have the following actors to function correctly:

Voter: Person who is entitled to vote. In many countries, citizens who are eligible to vote are those who are literate over the age of 18 and under the age of retirement in their country in some countries, this group is obligated to vote. People who are between the ages of 16 and 18 are allowed to exercise their right to vote, not being obligatory for retired or illiterate people.

Registration Authority: Authority responsible for ensuring the voting rights of voters. They provide real information of citizens who are duly registered and present the characteristics that consider them eligible to effectuate their right to vote.

Counting Authority: In Latin America, it is an obligation of the state to have various electoral institutions. They have the purpose of ensuring the planning and fulfillment of the elections, and controlling the registration of the different applicants to candidates and their respective associations during political operations from the moment it is decided to carry out an electoral process until the results are disseminated. In some cases, they are also in charge of providing the infrastructure to carry out the elections. These are usually the educational centers located near the residence of the voters to facilitate access at the time of the referendum.

Additionally, electoral systems regardless of the type should include five general phases:

Registration: It is the responsibility of the state that each country has a civil registry where all citizens are enrolled without any exception. This system allows you to collect the all kinds of information to determine if citizens have all the requirements that allow them to exercise their right to vote.

Authentication: Each electoral institution designates various authorities that comply with the verification of identifications of all those who attend to the designated election site. If the citizen presents the designated documents and complies with all the necessary regulations, then the responsible authority has the obligation to register that the voter has participated in the corresponding election.

Voting: At the time of voting, it must be taken into account that there are certain citizens who have a preference at the time of voting, such as people over 60 , ill people, pregnant women, people with disabilities, and women carrying children. In some countries, the law obliges people to vote. If a voter who is forced to vote does not show up, the voter will be in debt with the Electoral Justice.

Vote counting: Once the election period is over, the authorities in charge restrict the passage of people from outside the process and proceed to carry out the corresponding accounting of the votes. Depending on the country where the election takes place, the vote count can vary from hours to days, which generates concern among the citizens since the results can generate controversy when the information is filtered.

Results Delivery: Once the vote count has been carried out by the designated persons, the authorities belonging to the electoral institutions have the duty to verify if the results obtained in the previous process have coherence in order to formally disclose the results using the chosen means of communication.

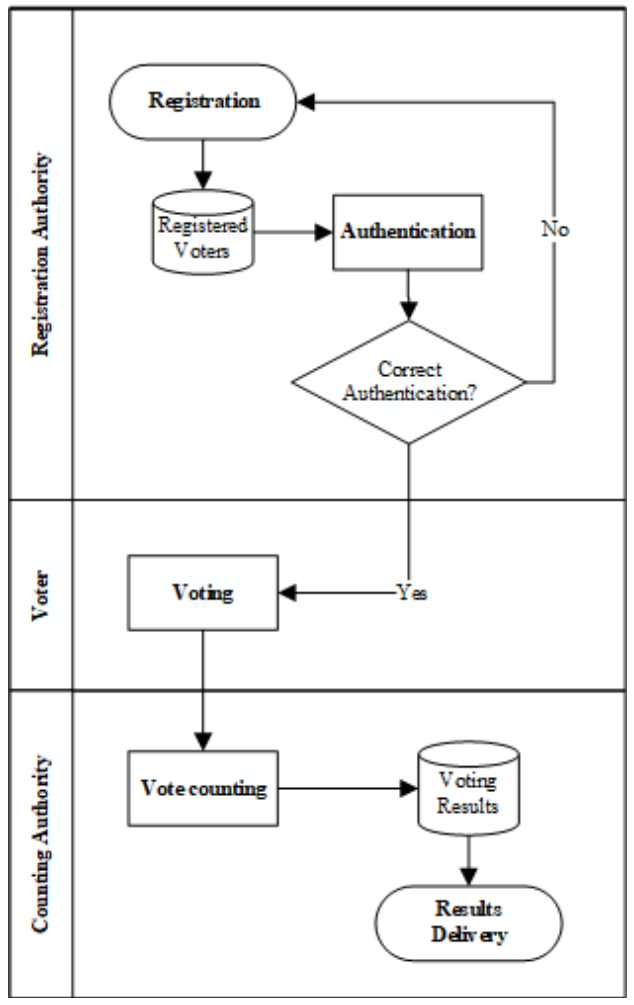

Figure 1: Electoral system Process Flow.

Figure 1 displays a general electoral system process flow regardless of type. It includes three different actors and five general phases, as discussed above.

Furthermore, according to [10] both voting systems consist of different types of rules which may differ depending on the country that performs the electoral process. There are mainly two types of electoral systems that define the voting rules independently of the voting system employed, the majority in which the one with the most votes wins and the proportional ones 
in which it is sought to ensure that the charges are distributed proportionally in relation to the number of votes received by competitors. There is a third type known as a mixed system that is the combination of certain characteristics and rules of the previous types.

In Latin America, the proportional election system is currently used. This is subdivided into a list and a single transferable vote and the mixed election system, which may be dependent or independent.

\section{- Majoritarian Systems}

As the name implies, are those in which the candidate or party with the greatest number of votes is chosen as the winner. This type of systems have the distinction of having two types of rules that can be applied to the same situation, such as the single member districts in which the winning candidate is the one with the most votes even though it does not exceed $50 \%$ of total votes.

This does not happen in the two-shift system that performs what is known as the second round when no candidate crosses the $50 \%$ barrier. When there is more than one seat available for political posts, multi-member models known as plurinominal district are used, where the voters can grant their vote to more than one candidate, taking care not to exceed the maximum number of seats. This type of model is used for the election of presidents, mayors, governors and senators.

\section{- Proportional Representation}

Unlike majority systems, the principle of the proportional model is to ensure that minor parties also achieve representation. These parties do not need to receive the majority of votes to be elected as indicated by the single transferable vote where the voter can vote for more than one party ranking their choices according to their preferences.

When counting, the first option of each voter is taken into account and the less voted parties votes are successively redistributed according to the order of choice. These proportional systems also have the voting list where each party presents a candidate list to the voter, depending on the country and the type of election that is being made. The voter is allowed to choose the party or a specific candidate from this list.

\section{- Mixed Systems}

Some countries such as Bolivia, Venezuela and Mexico have adopted mixed systems. They use proportional and majority models at the same time to elect representatives. The two models can be independent, if they exist in parallel, or dependent, if the voting rule of one system influences another. It is common that in mixed systems, voters must vote twice. The first uses a majority system as single member districts and the second implements a proportional representation system.

\subsection{Methods}

The Deductive Method has been used for this research. It has been possible to determine the threats and vulnerabilities that negatively affect electoral systems.

\section{Voting Systems Characteristics}

As stated in [11-13], the defining features that an election system must comply to be effective are the following:

\section{Anonymity of the voter}

The vote of a voter must remain secret. Everyone can know the voters and the candidates, but only the voters can know their votes. This means that no historical record of the voters' elections should be kept. In E-Voting systems, a digital record of the vote is used. This is an electronic record generated by the same ballot box that counts votes and fulfills the votes storing function without losing the characteristic of anonymity that the traditional voting system has.

If external agents wanted to know the identity of a particular voter, they should know the system in its minimum details for the extraction of the digital record. In order to visualize the original order of the votes' incoming, a computerized system records the time of access to the electronic ballot box. In order to carry out voter identification, it is only necessary to monitor the voting order of the voters and compare them with the entry record.

In most electronic voting processes, voter's credentials are usually encrypted, but total security does not exist. Originally, the servers of those who administer the voting can decrypt the original information. Therefore, in these cases the anonymity of the vote is not fully guaranteed.

\section{Detection of falsification of votes}

The system needs to be able to tell the difference between a false and a real vote. The ballot paper is audited manually in traditional referendums while in E-Voting is the system that needs to be able to differentiate.

According to experts, it is possible to produce the exchange of votes only with a movement generated by the operator of the system which would produce a falsification of votes. The destruction of hard drives of electronic voting is also a particular reason for doubt. As claimed by the specialist in IT (Information Technology) Märt Põder, electronic elections are a semiunprotected wall of a city [14].

\section{Detection of duplication of votes}

In the traditional system, voters can only vote once. It is necessary to keep a historical record of the people who voted, in order to keep track of the total number of votes and there are not duplicated votes.

However, if the electronic voting process does not have sufficient security guaranteed. In the case of DRE on public network, there is the possibility that different votes will be received from a single IP address, thus altering the results of the elections. There may also be the case of a family of several members, who share internet access, how can it be identified if the IP address belongs to one or more people?

\section{Integrity of the ballot paper}

Once the vote record is either saved, as a record in a database or placed in the voting booth, it cannot be changed. The extraction of this data is done through a mobile medium. This medium contains the data of the whole voting process. Once the whole process is finished, the ballot box prints the result of that electoral section. 
In this way, the result of the election becomes transparent and of public knowledge as soon as voting is completed. This procedure occurs simultaneously in all the electoral sections.

Some countries use the electronic voting system using ballot boxes that do not possess Internet connection or any means of data transmission, being the only cable connected to this the power cord. Moreover, if necessary, it may only be connected to an auxiliary battery for example, if power is missing.

Imagine a safe in which a large sum of money is saved. To find out if the content has changed, simply count the money and compared with the balance stored on paper in your wallet. If the values are not equal, it means that the balance or contents of the safe have changed. The electronic ballot box would be a safe in which the balance and the money are stored in the same place. In case someone can open the safe, it would be possible to withdraw the money and at the same time, change the balance written on the paper to reflect the new value. In this way, it would be difficult to detect that the safe was compromised.

\section{Voting availability}

One of the indispensable principles that should guide elections with electronic votes is the absolute availability which ensures that elections cannot be postponed or temporarily interrupted by unavailability of the ballot boxes. They must be stable and secure enough so that the entire voting process takes place during the date and time set by the government. Therefore, the voter is able to exercise his right to vote within the date and time established by the institution in charge.

\section{Accuracy in the count}

In countries with a particularly dense population that use the traditional system, the voting and counting process takes several weeks increasing the uncertainty in the voters. The electronic voting systems allow the population to know the results in a shorter time. This can generate more confidence because the votes cannot be altered, duplicated or eliminated without this action going unnoticed.

The electronic voting system will not allow invalid votes to be counted nor included in the results. In DRE systems, the process of registering and counting votes is free of human errors, and just as in the traditional voting system, the total of votes must be equal to the total of voters who attended to vote.

\section{Security in the system}

The electoral system needs to be resistant against failures and attacks. Corruption attempts by authorities, voters, and hardware or software failures should not affect the system.

Inevitably, exhaustive discussions have been raised regarding the current consequences that the use of computer technology can have for the security and integrity of the election process.

Moreover, malicious software can alter the electronic printing on the screen altering the voter eagerness to cast a vote. In the same way, an intruder can manipulate the outcome of the results. People who oppose or challenge E-Voting give several reasons supposed flaws which might influence the accuracy of the electoral process.

Nevertheless, several technical answers ensure that these exploitable vulnerabilities are entirely fictitious. Depending on the used system, traditional voting may be more susceptible to alterations than an efficient E-Voting system.
When the E-Voting systems are subject to external security audits, cases of adulteration of votes and registers are frequent. As no system is free from attacks, public administrations are not exempt from the fact that their institutional IT security can be attacked or violated. Thus, it is essential the developing of a voting system capable of resisting attacks and failures, as well as not being affected by corruption attempts by internal and external agents such as the authorities, voters or even programmers.

\section{Simplicity of use}

One of the most important characteristics when implementing the electronic voting system is to facilitate citizens the possibility of participating in democratic processes, encouraging them not to abstain and increasing the total records. In addition, the system must be simple enough for anyone to use it. Its simplicity is also an advantage for those citizens with limited or non-existent technical skills, disabled voters and citizens residing in a city other than their own to vote.

\section{Voting Systems Vulnerabilities}

In $[11,13-17]$ several vulnerabilities within the Voting systems are identified, being the most important:

\section{Social engineering}

It is a term that describes attacks that are based on deceiving a person so they willingly hand over their private data without realizing it. For example in the real world, criminals by searching your garbage can steal your personal information, thus finding sensitive data and carrying out transactions with them.

Figuring out the name of your pet, school, or any other information that may be used as a security question in the accounts of the Internet, your account may be compromised. These are attacks identified as low level, but they are still methodical and successful attacks.

\section{Digital Division}

The world in which we live is separated by the barrier of technology. This affects not only the underdeveloped countries or the rural class, but also the developed countries. In the Internet era, this is called a digital division. Despite the efforts that are being made to equip societies and citizens with digital technologies, the truth is that there are profound inequalities at international, national, regional and local levels. Digital divisions influence the process of electronic voting. Households with Internet and those who do not possess it, faster connection than others are clear examples of digital divisions. This will directly affect the capacity of access the system.

\section{Security problems related to the client and the server}

It can never be assumed that the user's computer is completely secure. Due to the architecture of current systems, it is possible for external agents to use various mechanisms to infiltrate users' systems in the form of viruses that allow them to spy on the ballots, prevent voters from voting, or directly modify the votes.

However, there are countries that offer a solution for this type of altercations. They offer special open source and secure voting systems so the state is responsible for the electronic machine software at the operating system level. These provides voting booths or special machines that have a much lower probability of doing something wrong due to viruses or the inappropriate use of computers. 


\section{Security problems related to the connection}

The connection refers to the link between the client who votes and the server which is responsible for counting the votes.

One of the main problems when using the electronic voting system is the distrust in the reliability of the system. Many people believe that it is safer to carry out the voting in a traditional way since there is a connection between the voter and the authority responsible for votes counting instead of using a machine that collects and analyzes the votes quickly and efficiently. To grant the corresponding results in the least amount of time possible. For DRE on public network, this link must be trusted and secure for as long as the records are being delivered to the server.

\section{Vote purchase}

There are many disadvantages in any type of voting. The security of electronic voting is of the most criticized, not for only being vulnerable to internal attacks but also for the possibility that external agents collects votes by any means. They do it either directly, in a way of coercion or threats or indirectly imposing the delusion that the candidate is good. This usually involves giving salaries, gifts or assignments for specific services to potential voters, such as distributing notes, and hanging posters.

Currently there is no real protection for the problem of buying votes in any of the electoral systems because it is much easier to organize than discover it.

\section{Disenfranchisement}

In agreement with the law in certain countries, the voting rights for people or a specific group of individuals is restricted. This in some cases can occur without legal basis due to incoordination or mismanagement, deliberately or involuntarily. It can be given in the case of people who are deprived of liberty and are not disqualified to vote. The decision to restrict this right is due to the fact that people who are deprived of their liberty have committed a crime that violates the constitutional laws that govern a country and therefore they are not allowed to participate in processes that would compromise society as such.

\section{Handling of the Voter's data}

It consists in manipulating the information of the voter to harm it. This information may be demographic or historical data which can be used by political entities to postulate content that favor the political campaign in their favor. The E-Voting is done through machines using software that records vote information that could be manipulated. For example, when we pay a ticket at the Bank, we can save the voucher or receipt in a PDF file. If the same fee is subsequently charged again, the voucher allows proving that the debt has been paid. Would you trust a bank that after paying a ticket the money simply disappeared from your balance without the destination of that money being at least registered in your bank record? Most likely the answer would be no.

Similarly, the electoral system used in Brazil has exactly that problem so it has decided to implement anonymous vouchers that allow the user to ensure that their vote has been made with satisfaction for the comparison of the values recorded in the electronic memory.

\section{Ballot Tracking}

When conducting an electoral process, one of the guidelines is to ensure that the materials provided by the authorities are protected and in good condition. They are designated to various groups of Special Forces such as military, navy, police and others to monitor them by preventing other individuals from doing scrupulous acts that can compromise the elections.

This event of ballot tracking is done when the designated sites by the electoral institutions do not have the necessary equipment to perform the final vote counting that will indicate the results.

\section{Ballot Stuffing}

The filling of ballots is one of the vulnerabilities of the traditional voting system. Many citizens are determined to commit electoral fraud so that their preferred candidate can win. This happens when they do not have control of what happens in the ballot box since this individual could be carrying their own ballots or the person in charge of administering the ballots could adulterate them and pass them off as votes of absentees. Depending on the country, the penalty varies between months up to 10 years.

\section{Digital Illiteracy}

Around millions of people in Latin America lose their connection in an increasingly digital world. Mainly, people who live in the rural regions of their country and people over 55. This lack of knowledge in the digital age does not allow them to enjoy a variety of benefits without the need to get assistance from a person who has the capabilities to help.

In recent years, several government institutions offer services via the Internet to streamline all types of processes. Therefore, if the person cannot function quickly and efficiently in the digital world, he/she is marginalized from the rest of their social environment.

\section{Results}

In the present work, it can be deduced that any of the two voting systems presents characteristics and vulnerabilities that must be considered when trying to implement a system that satisfies all the requirements that are needed for a satisfactory electoral process.

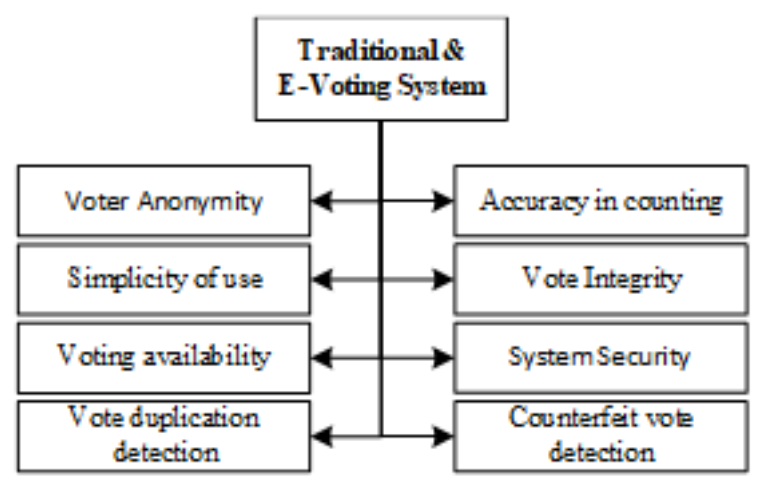

Figure 2: Characteristics of voting systems.

Figure 2 contains a diagram with eight characteristics of both voting systems, and these must be present when using any of them. If one of these fails, the results of the election could be compromised.

Likewise, Figure 3 displays a diagram of the weaknesses affecting the two varying types of electoral systems. Both systems 
have different vulnerabilities. Some of these vulnerabilities are shared among them.

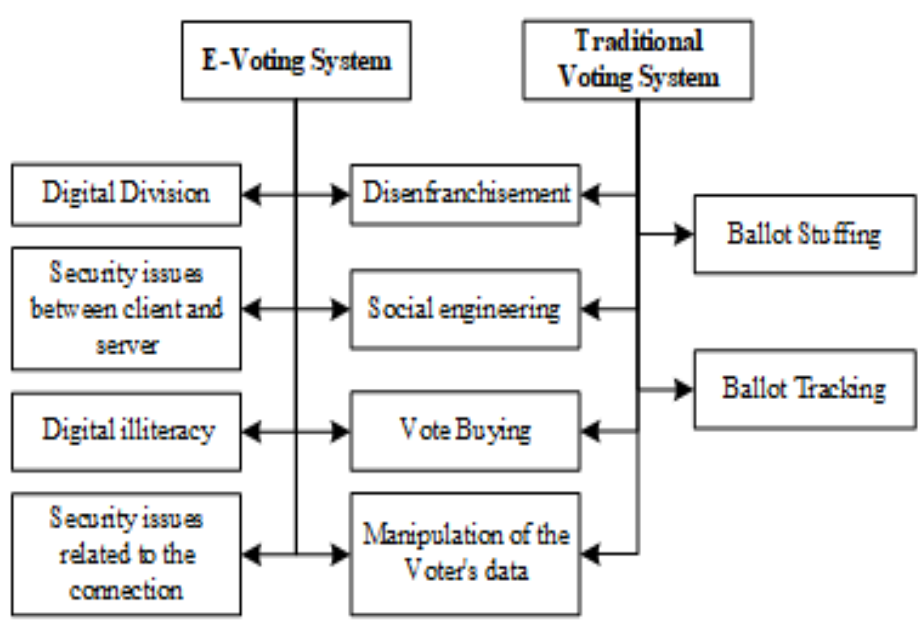

Figure 3: Vulnerabilities affecting the voting systems.

Therefore, it is discernible that half of the vulnerabilities present in E-Voting are related to the appropriate management of technology while the other vulnerabilities presented in both systems are related to society. This leads to understanding that the traditional voting system is more exposed to human error and/or social interference.

Table 2 defines the different levels of criticality of voting systems. Four levels have been considered which are separated by color code.

Subsequently in Table 3, the various risks affecting the systems are detailed and grouped by type of risks and levels of criticality. As can be seen, the E-Voting system presents two types of risk that would have a great impact on society while the traditional voting system does not have that kind of impact. Social risk influences each of the risks present in both types of voting system. This means, society is the one that decides whether the chosen voting system is going to be successful or not. Both systems present the same amount of moderate risk. As a result, the three risks that do not compromise the system belong to the E-Voting system and are not subject to technological errors.
Table 2: Criticality levels

\begin{tabular}{|c|c|c|}
\hline Impact & Description & Color Code \\
\hline $\begin{array}{l}\text { Very } \\
\text { Severe }\end{array}$ & $\begin{array}{l}\text { The risk is high, directly affects } \\
\text { the voting system and can change } \\
\text { the outcome of the vote. }\end{array}$ & Red \\
\hline Serious & $\begin{array}{l}\text { The risk is moderate and can alter } \\
\text { the outcome of the election if it is } \\
\text { not detected and corrected on } \\
\text { time. }\end{array}$ & Orange \\
\hline Moderate & $\begin{array}{l}\text { The risk is minor and does not } \\
\text { directly affect the voting system. }\end{array}$ & Yellow \\
\hline Mild & $\begin{array}{l}\text { The system has not been } \\
\text { jeopardize. }\end{array}$ & Green \\
\hline
\end{tabular}

The voting systems, when fulfilling these characteristics, can mitigate their inherent vulnerabilities thus eliminating the hazard and dangers presented when implemented.

Pursuant to the data collected and exposed by governments in historical reports [18 - 28] in Table 4A and Table 4B, it can be observed the citizen participation in the 3 selected countries. There were several electoral processes in the election of Presidents and Vice-presidents made every 4 years. In 10 out of 12 elections, a second round was necessary for the election of its president.

In conducting the research, work was concluded that there are big gaps over the time to take, collect, organize, and disseminate the results depending on the type of voting system used in each country.

Table 5 data shows a comparison between each of the countries. For example, between Brazil and Colombia, Colombia represents only $23.30 \%$ of registered voters whereas in Brazil only $49.64 \%$ registered voters showed up to exercise their right to vote.

Comparing the countries of Ecuador and Colombia, they present a difference of $30.85 \%$ in citizen participation. Although according to Table 1, Colombia has a greater population than Ecuador. Less than half of the registered individuals in Colombia vote. The collection and dissemination of results may take between 9 to 10 hours less than in Ecuador.

Table 3: Risks affecting voting systems.

\begin{tabular}{|l|c|c|c|}
\hline \multicolumn{1}{|c|}{ Risk } & System & Type of Risk & Impact \\
\hline Security issues related to the connection & E-Voting & Technological/ Social & Very Severe \\
Related security issues with the client and the server & E-Voting & Technological/ Social & Very Severe \\
\hline Social engineering & E-Voting / Traditional & Social & Serious \\
\hline Ballot Tracking & Traditional & Social & Serious \\
\hline Ballot Stuffing & Traditional & Social & Serious \\
\hline Manipulation of the Voter's data & E-Voting / Traditional & Technological/ Social & Serious \\
\hline Vote Buying & E-Voting / Traditional & Social & Moderate \\
\hline Disenfranchisement & E-Voting / Traditional & Social & Mild \\
\hline Digital Division & E-Voting & Technological/ Social & Mild \\
\hline Digital illiteracy & E-Voting & Technological/ Social & Mild \\
\hline
\end{tabular}


S.M.T Toapanta et al. / Advances in Science, Technology and Engineering Systems Journal Vol. 4, No. 3, 106-116 (2019)

Table 4A: Results of the three last presidential elections in Brazil, Colombia and Ecuador (First Round).

\begin{tabular}{|c|c|c|c|c|c|c|c|c|c|}
\hline \multirow{2}{*}{$\begin{array}{l}\text { Presidential } \\
\text { Elections }\end{array}$} & \multicolumn{3}{|c|}{ BRAZIL } & \multicolumn{3}{|c|}{ COLOMBIA } & \multicolumn{3}{|c|}{ ECUADOR } \\
\hline & 2010 & 2014 & 2018 & 2010 & 2014 & 2018 & 2009 & 2013 & 2017 \\
\hline Registered voters & 135804084 & 142822046 & 147299471 & 29997574 & 33023716 & 36227267 & 10529765 & 11675441 & 12816698 \\
\hline Valid votes & 101590153 & 104023802 & 107050749 & 14573593 & 12160881 & 19336134 & 6897912 & 8602603 & 9442495 \\
\hline Blank votes & 3479340 & 4420489 & 3106937 & 261530 & 672782 & 338581 & 534149 & 179230 & 286069 \\
\hline Null votes & 6124254 & 6678592 & 7206968 & 170874 & 351739 & 242002 & 496687 & 684027 & 736743 \\
\hline Total Voters & 111193747 & 115122883 & 117364654 & 15005997 & 13185402 & 19916717 & 7928748 & 9465860 & 10465307 \\
\hline
\end{tabular}

Table 4B: Results of the three last presidential elections in Brazil, Colombia and Ecuador (Second Round)

\begin{tabular}{|c|r|c|r|r|r|r|r|}
\hline \multirow{2}{*}{$\begin{array}{c}\text { Presidential } \\
\text { Elections }\end{array}$} & \multicolumn{3}{|c|}{ BRAZIL } & \multicolumn{3}{c|}{ COLOMBIA } & ECUADOR \\
\cline { 2 - 8 } & \multicolumn{1}{c|}{$\mathbf{2 0 1 0}$} & $\mathbf{2 0 1 4}$ & \multicolumn{1}{c|}{$\mathbf{2 0 1 8}$} & \multicolumn{1}{c|}{$\mathbf{2 0 1 0}$} & \multicolumn{1}{c|}{$\mathbf{2 0 1 4}$} & \multicolumn{1}{c|}{$\mathbf{2 0 1 8}$} & \multicolumn{1}{c|}{$\mathbf{2 0 1 7}$} \\
\hline Registered voters & 135804084 & 142822046 & 147299471 & 29997574 & 33023716 & 36227267 & 12816698 \\
\hline Valid votes & 99463917 & 105542273 & 104838753 & 13061192 & 15341383 & 19247062 & 9895407 \\
\hline Blank votes & 2452597 & 1921819 & 2486593 & 482003 & 619396 & 807924 & 69436 \\
\hline Null votes & 4689428 & 5219787 & 8608105 & 198003 & 403405 & 265857 & 670731 \\
\hline Total Voters & 106605942 & 112683879 & 115933451 & 13741198 & 16364184 & 20320843 & 10635574 \\
\hline
\end{tabular}

However, it should be taken into account that both Brazil and Ecuador use electronic voting systems. Being DRE and automated paper-based voting respectively, where according to Table 5, Ecuador has a $5.62 \%$ more participation in relation to Brazil.

Table 5: Average of the collected data.

\begin{tabular}{|c|r|r|r|}
\hline \multirow{2}{*}{$\begin{array}{c}\text { Presidential } \\
\text { Elections }\end{array}$} & \multicolumn{1}{|c|}{ Brazil } & Colombia & Ecuador \\
\cline { 2 - 4 } & \multicolumn{3}{|c|}{ Average } \\
\hline Registered voters & 141975200 & \multicolumn{1}{|c|}{33082852} & 11673968 \\
\hline \multicolumn{4}{|c|}{ First Round } \\
\hline Valid votes & 104221568 & 15356869 & 8314337 \\
\hline Blank votes & 366822 & 424298 & 333149 \\
\hline Null votes & 6669938 & 254872 & 639152 \\
\hline Total Voters & 114560428 & 16036039 & 9286638 \\
\hline \multicolumn{4}{|c}{ Second Round } \\
\hline Valid votes & 103281648 & 15883212 & 9895407 \\
\hline Blank votes & 2287003 & 636441 & 69436 \\
\hline Null votes & 6172440 & 289088 & 670731 \\
\hline Total Voters & 111741091 & 16808742 & 10635574 \\
\hline Average Turnout & $79.71 \%$ & $49.64 \%$ & $85.33 \%$ \\
\hline
\end{tabular}

\section{Discussion}

Since 1992, Latin America has decided to be part of technological change. This is why some countries undertook the adaptation process to migrate from the traditional voting system to E-Voting.

According to the data provided by the different counting authorities [29-32], Table 6 shows that around 11 countries decided to implement and register pilot tests from 1992 to 2018. Only Brazil and Venezuela decided the implementation of EVoting in their current government.

www.astesj.com
Table 6: E-Voting pilots in Latin America.

\begin{tabular}{|c|c|c|}
\hline COUNTRY & Pilot Year & E-Voting \\
\hline Colombia & 1992 & DRE \\
\hline Brazil & 1996 & DRE \\
\hline Peru & 1996 & DRE \\
\hline Venezuela & 1998 & DRE \\
\hline Paraguay & 2001 & DRE \\
\hline Venezuela & 2002 & DRE \\
\hline Costa Rica & 2002 & DRE \\
\hline Argentina & 2003 & DRE \\
\hline Ecuador & 2004 & Paper Based \\
\hline Dominican Republic & 2006 & DRE \\
\hline Mexico & 2006 & DRE \\
\hline Argentina & 2011 & DRE \\
\hline Argentina & 2013 & DRE \\
\hline Ecuador & 2014 & DRE \\
\hline Panama & 2014 & DRE \\
\hline Argentina & 2015 & DRE \\
\hline Peru & 2015 & DRE \\
\hline Peru & 2018 & DRE \\
\hline Colombia & 2018 & DRE \\
\hline
\end{tabular}

In the present investigation, it was decided to use Brazil as a model representative of the Latin American countries using the electronic voting system in its entirety. Venezuela has been excluded, due to its current situation which has not allowed the collection of electoral data from reliable and truthful sources. It should also be noted that Argentina has made about 4 documented pilot tests, but it has not yet been able to migrate satisfactorily towards electronic voting.

Also in the analysis that has been carried out in the present investigation, the characteristics and vulnerabilities of the 
traditional system and the E-voting, indicated in Figure 2 and Figure 3 respectively, have been established. They take into consideration that all the characteristics are necessary for the correct functionality of both systems. Voting Integrity and System Security have been identified as the most fundamental characteristics in voting systems. The main reason for this is that the integrity of the vote ensures that the election is conducted in an anonymously, safely and transparent manner. On the other hand, the security of the system assures that the entire electoral process is free of faults, so safeguarding its effectiveness.

Table 7: Last presidential election time details.

\begin{tabular}{|c|c|c|c|c|c|}
\hline Country & $\begin{array}{c}\text { Election } \\
\text { Date }\end{array}$ & Begin & End & $\begin{array}{c}\text { Vote } \\
\text { Tallying }\end{array}$ & $\begin{array}{c}\text { Tallying } \\
\text { time }\end{array}$ \\
\hline Brazil & $28 / 10 / 2018$ & $8: 00$ & $17: 00$ & $\begin{array}{c}28 / 10 / 2018 \\
19: 13\end{array}$ & $2: 13: 00$ \\
\hline Colombia & $17 / 6 / 2018$ & $8: 00$ & $16: 00$ & $\begin{array}{c}17 / 6 / 2018 \\
19: 51\end{array}$ & $3: 51: 45$ \\
\hline Ecuador & $2 / 4 / 2017$ & $7: 00$ & $17: 00$ & $\begin{array}{c}3 / 4 / 2017 \\
6: 06\end{array}$ & $13: 06: 00$ \\
\hline
\end{tabular}

However, it must be taken into account that both Brazil and Ecuador uses E-Voting systems. Additionally, Ecuador represents only $8.22 \%$ of registered voters of Brazil, where according to Table 5 only the $85.33 \%$ show up to vote. Nevertheless, the differences of the various types of E-Voting are reflected in the last two phases. These are the vote counting and the results delivery. According to Table 7 [33-35], we can consider a time factor of 6.13 which equals to 11 hours. In addition, by continuing to use the traditional voting system, Colombia takes 1.38 more hours than Brazil in vote counting depending on the type of system and the authority in charge.

\section{Future work}

In Ecuador, Article 292 of the Organic Electoral Law of Democracy [36] determines that if people who have the obligation to vote do not show up to vote, they will be sanctioned with $10 \%$ of their basic salary. On the other hand, in Brazil article 7 of the electoral code [37] dictates that the citizen must justify his fault before a judge where he will decide the percentage of the fine between $3 \%$ and $10 \%$ of the minimum wage.

Therefore, it is recommended to conduct a study analyzing the probability that the participation of citizens in choosing their leader is related to the reliability of the voting system or the penalty fee for not exercising their right to vote.

The gradual increase in corruption in Latin America [38] is one of the most relevant facts that is not been considered from a technical point of view, but it still should be considered. In Figure 4 , the country corruption indices by country can be observed. Venezuela leads the list with $87 \%$, while Argentina is last with an index of $41 \%$.

As it can be seen in Table 6, Latin America has not conducted a pilot test for the E-Voting System DRE in public network. It is necessary that future research focus on the development of new methodologies and technologies so that it can be correctly implemented.

\section{Conclusions}

The countries of Latin America that have decided to use both partially and fully E-Voting system have come to the conclusion that once vulnerabilities have been mitigated it becomes the least risky and most efficient to implement. It is a safe, transparent and auditable process.

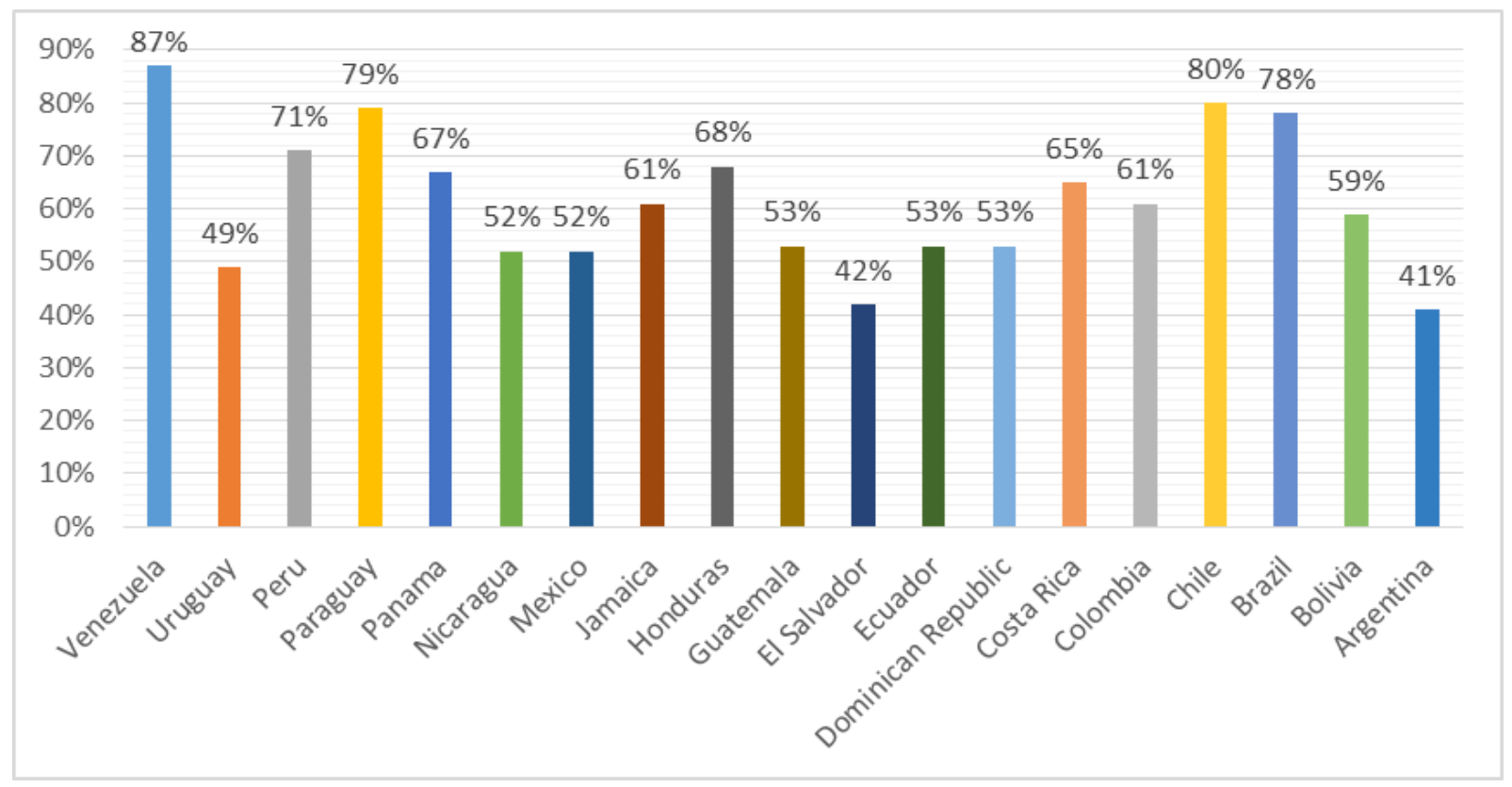

Figure 4: Corruption Indices by Country in Latin America. 
Taking into account, voting systems consist of five phases as shown in Figure 1. In the automated paper-based voting, four of these phases are directly linked to the margin of human error while in the other two types of E-Voting the whole process is electronic. It can be discerned that DRE and DRE on public network reduces voting time which leads to the reduction of operational costs. Finally, it was concluded that to alleviate the potential risks of voting systems is necessary to identify and neutralize the weaknesses in the E-Voting system. This can be considered as an alternative approach to increase the security of the process.

Hence, when implementing this type of system, it is essential to consider the security requirements. With this in mind, without the appropriate measures E-Voting can be a real challenge.

\section{Acknowledgment}

The authors thanks to Universidad Politécnica Salesiana del Ecuador, to the research group of the Guayaquil Headquarters "Computing, Security and Information Technology for a Globalized World" (CSITGW) created according to resolution 142-06-2017-07-19 and Secretaría de Educación Superior Ciencia, Tecnología e Innovación (Senescyt).

\section{Appendix}

Appendix: Articles and books reviewed in relation to the subject.

\begin{tabular}{|l|c|}
\hline \multicolumn{1}{|c|}{ Title } & $\begin{array}{c}\text { Publication } \\
\text { Year }\end{array}$ \\
\hline $\begin{array}{l}\text { E-voting en Colombia: Avances y desafíos en la } \\
\text { implementación. }\end{array}$ & 2019 \\
\hline $\begin{array}{l}\text { A Scheme for Three-way Secure and Verifiable } \\
\text { E-Voting. }\end{array}$ & 2019 \\
\hline $\begin{array}{l}\text { The Electoral Success of the Left in Latin } \\
\text { America: Is there any room for Spatial Models of } \\
\text { Voting? }\end{array}$ & 2019 \\
\hline Electronic voting & 2018 \\
\hline $\begin{array}{l}\text { The Good, the Bad, and the Ugly: Two Decades } \\
\text { of E-Voting in Brazil }\end{array}$ & 2018 \\
\hline $\begin{array}{l}\text { Towards a Secure Online E-voting Protocol } \\
\text { Based on Palmprint Features. }\end{array}$ & 2018 \\
\hline $\begin{array}{l}\text { Secured and transparent voting system using } \\
\text { biometrics. }\end{array}$ & 2018 \\
\hline $\begin{array}{l}\text { Election fraud and privacy related issues: } \\
\text { Addressing electoral integrity. }\end{array}$ & 2017 \\
\hline Principles of comparative politics & 2017 \\
\hline Smart voting & 2017 \\
\hline Electronic Voting. & 2017 \\
\hline Towards security modeling of E-voting systems & 2016 \\
\hline $\begin{array}{l}\text { Digital divide impact on e-voting adoption in } \\
\text { middle eastern country. }\end{array}$ & 2016 \\
\hline $\begin{array}{l}\text { Identification of Non-Functional Requirements } \\
\text { for Electronic Voting Systems: A Systematic } \\
\text { Mapping. }\end{array}$ & 2015 \\
\hline $\begin{array}{l}\text { From piloting to roll-out: Voting experience and } \\
\text { trust in the first full e-election in Argentina. }\end{array}$ & 2014 \\
\hline $\begin{array}{l}\text { Trust in elections, vote buying, and turnout in } \\
\text { Latin America. }\end{array}$ & 2013 \\
\hline
\end{tabular}

\section{References}

[1] D. F. Aranha and U. Estadual, "The Good, the Bad, and the Ugly: Two Decades of E-Voting in Brazil," no. December 2018, 2019.

[2] A. Kiayias, "Electronic voting," Handb. Financ. Cryptogr. Secur., no. October 2018, pp. 59-82, 2010. https://doi.org/10.1201/9781420059823.

[3] C. D. De Faveri, A. Moreira, J. Araújo, and V. Amaral, "Towards security modeling of E-voting systems," Proc. - 2016 IEEE 24th Int. Requir. Eng. Conf. Work. REW 2016, pp. 145-154, 2017. https://doi.org/10.1109/REW.2016.37.

[4] J. Pomares, I. Levin, R. Alvarez, G. Mirau, and T. Ovejero, "From piloting to roll-out: Voting experience and trust in the first full e-election in Argentina," 2014 6th Int. Conf. Electron. Voting Verif. Vote, EVOTE 2014 IEEE Proc., 2015. https://doi.org/10.1109/EVOTE.2014.7001136.

[5] F. P. Pardo, "E-voting in Colombia: Progress and challenges in its implementation [E-voting en Colombia: Avances y desafios en la implementación]," Rev. Derecho del Estado, no. 42, pp. 211-248, 2019. https://doi.org/10.18601/01229893.n42.08.

[6] S. E. E. Profile, "The Electoral Success of the Left in Latin America : Is there any room for Spatial The Electoral Success of the Left in Latin America: Is there any room for Spatial Models of Voting ? *," no. April, 2019.

[7] M. Carreras and Y. Irepoğlu, "Trust in elections, vote buying, and turnout in Latin America," Elect. Stud., vol. 32, no. 4, pp. 609-619, 2013. https://doi.org/10.1016/j.electstud.2013.07.012.

[8] M. Nassar, Q. Malluhi, and T. Khan, "A Scheme for Three-way Secure and Verifiable E-Voting," Proc. IEEE/ACS Int. Conf. Comput. Syst. Appl. AICCSA, vol. 2018-Novem, pp. 1-6, 2019. https://doi.org/10.1109/AICCSA.2018.8612810.

[9] A. Meraoumia, H. Bendjenna, M. Amroune, and Y. Dris, "Towards a Secure Online E-voting Protocol Based on Palmprint Features," Proc. - PAIS 2018 Int. Conf. Pattern Anal. Intell. Syst., pp. 1-6, 2018. https://doi.org/10.1109/PAIS.2018.8598520.

[10] W. R. Clark, M. Golder, and S. N. Golder, Principles of comparative politics, 3rd Revised Edition. Washington, United States: SAGE Publications Inc, 2017

[11] S. Sepulveda, M. Bustamante, and A. Cravero, "Identification of NonFunctional Requirements for Electronic Voting Systems: A Systematic Mapping," IEEE Lat. Am. Trans., vol. 13, no. 5, pp. 1577-1583, 2015. https://doi.org/10.1109/TLA.2015.7112018.

[12] M. Lubis, M. Kartiwi, and S. Zulhuda, "Election fraud and privacy related issues: Addressing electoral integrity," 2016 Int. Conf. Informatics Comput. ICIC 2016, no. Icic, pp. 227-232, 2017 https://doi.org/10.1109/IAC.2016.7905720.

[13] C. J. Lakshmi and S. Kalpana, "Secured and transparent voting system using biometrics," Proc. 2nd Int. Conf. Inven. Syst. Control. ICISC 2018, no. Icisc, pp. 343-350, 2018. https://doi.org/10.1109/ICISC.2018.8399092.

[14] V. Lepassalu, "IT-EKSPERDID ÜLISTATUD E-HÄÄLETUSEST: Valijate hääli saab võltsida ühe näpuliigutusega, süsteem on kui katkine linnamüür!,” 2017. [Online]. Available: http://www.pealinn.ee/tagid/koik/iteksperdid-ulistatud-e-haaletusest-valijate-haali-saab-voltsida-n191310. [Accessed: 25-Apr-2019].

[15] J. Epstein, "Electronic Voting," vol. 10615, 2017. https://doi.org/10.1007/978-3-319-68687-5.

[16] W. Tambaram, "Smart voting," pp. 143-147, 2017.

[17] M. K. Alomari, "Digital divide impact on e-voting adoption in middle eastern country," 2016 11th Int. Conf. Internet Technol. Secur. Trans. ICITST 2016, pp. 409-412, 2017. https://doi.org/10.1109/ICITST.2016.7856741.

[18] Consejo Nacional Electoral, "ELECCIONES PRESIDENCIALES 2006 ELECCIONES PRESIDENCIALES 2009," 2009. [Online]. Available: cne.gob.ec/es/estadisticas/publicaciones/category/1285-eleccionespresidenciales-del-ecuador-1948-2017?download=2012:rafael-correadelgado. [Accessed: 24-Apr-2019].

[19] Consejo Nacional Electoral, "ELECCIONES PRESIDENCIALES 2017," $2017 . \quad$ [Online].

cne.gob.ec/es/estadisticas/publicaciones/category/1285-eleccionespresidenciales-del-ecuador-1948-2017?download=2013:lenin-morenogarces. [Accessed: 24-Apr-2019].

[20] Tribunal Superior Eleitoral, "Divulgação de Resultados de Eleições," 2018. [Online]. Available: divulga.tse.jus.br/oficial/index.html. [Accessed: 25Apr-2019].

[21] Registraduría Nacional del Estado Civil, "República de Colombia Elección Presidente y Vicepresidente - 30 de mayo de 2010," 2010. [Online] Available: 
https://www.registraduria.gov.co/elecciones_anteriores/2010PR/escrutinio. php. [Accessed: 24-Apr-2019].

[22] Registraduría Nacional del Estado Civil, "República de Colombia Elección Presidente y Vicepresidente - Segunda Vuelta - 20 de junio de 2010,” 2010. [Online]. Available: https://www.registraduria.gov.co/elecciones_anteriores/2010PR2/escrutinio .php\#. [Accessed: 24-Apr-2019].

[23] Registraduría Nacional del Estado Civil, "Escrutinio Presidente 1ra Vuelta," $2014 . \quad$ [Online]. Available: https://elecciones.registraduria.gov.co/esc_pre1v_2014/.

[24] Registraduría Nacional del Estado Civil, "Escrutinio Presidente 2da Vuelta," $2014 . \quad$ [Online]. Available: https://elecciones.registraduria.gov.co/esc_pre2v_2014/.

[25] Registraduría Nacional del Estado Civil, "ELECCIÓN DE PRESIDENTE 2018," 2018. [Online]. Available: http://elecciones1.registraduria.gov.co/esc_pre_1v_2018/. [Accessed: 24May-2019].

[26] Registraduría Nacional del Estado Civil, "ELECCIÓN DE PRESIDENTE SEGUNDA VUELTA 2018," 2018. [Online]. Available: http://elecciones1.registraduria.gov.co/esc pre 2v 2018/. [Accessed: 24Apr-2019].

[27] Tribunal Superior Eleitoral, "Estatísticas e Resultados da Eleição," 2010. [Online]. Available: http://www.tse.jus.br/hotsites/estatistica2010/est resultados.html. [Accessed: 25-Apr-2019].

[28] Tribunal Superior Eleitoral, "Informações e sobre as eleições 2014 Dados Estatísticos," resultados presidentes, 2014.

[29] INFOBAE, "Salta vota para elegir concejales, diputados y senadores provinciales," $2013 . \quad$ [Online]. Available: https://www.infobae.com/2013/11/10/1522618-salta-vota-elegirconcejales-diputados-y-senadores-provinciales/. [Accessed: 26-Apr-2019].

[30] El Comercio, "Se ejerció el voto electrónico en la cárcel de Cuenca," 2014. [Online]. Available: https://www.elcomercio.com/actualidad/politica/seejercio-voto-electronico-carcel.html. [Accessed: 25-Apr-2019].

[31]El Comercio, "Mi Perú usa el voto electrónico para elegir a su primer alcalde," 2015. [Online]. Available: https://elcomercio.pe/lima/mi-peru-votoelectronico-elegir-primer-alcalde-247817.

[32] EL UNIVERSAL, "Confirma INE que no habrá voto por Internet en 2018," $2017 . \quad$ [Online]. Available: https://www.eluniversal.com.mx/articulo/nacion/politica/2017/03/15/confir ma-ine-que-no-habra-voto-por-internet-en-2018. [Accessed: 25-Apr-2019].

[33] El Mercurio, "Revive el 'En tiempo real' de la elección que terminó con Bolsonaro presidente de Brasil.," 2018. [Online]. Available: https://www.emol.com/noticias/Internacional/2018/10/28/925529/Eleccionpresidencial-en-Brasil.html\%0A. [Accessed: 25-Apr-2019].

[34] EL TIEMPO, "Iván Duque es el nuevo Presidente: reviva aquí la jornada." [Online]. Available: https://www.eltiempo.com/elecciones-colombia2018/presidenciales/resultados-elecciones-presidenciales-2018-colombiasegunda-vuelta-231720. [Accessed: 26-Apr-2019].

[35] EL UNIVERSO, "CNE declara ganador de presidencia de Ecuador a Lenín Moreno, con 99,65\% de votos escrutados.," 2017. [Online]. Available: https://www.eluniverso.com/noticias/2017/04/04/nota/6123701/9965votos-cne-proclama-ganador-presidencia-ecuador-lenin-moreno. [Accessed: 25-Apr-2019].

[36] ASAMBLEA NACIONAL, "LEY ORGANICA ELECTORAL, CODIGO DE LA DEMOCRACIA," 2009. [Online]. Available: www.lexis.com.ec/wp-content/uploads/2018/07/LI-LEY-ORGANICAELECTORAL-CODIGO-DE-LA-DEMOCRACIA.pdf.

[37] Tribunal Superior Eleitoral, "Código Eleitoral - Lei n ${ }^{\circ} 4.737$, de 15 de julho de 1965,” $1965 . \quad$ [Online]. Available: http://www.tse.jus.br/legislacao/codigo-eleitoral/codigo-eleitoral-1/codigoeleitoral-lei-nb0-4.737-de-15-de-julho-de-1965. [Accessed: 27-Apr-2019].

[38] C. Pring, Las personas y la corrupción: América Latina y El Caribe. 2017. https://doi.org/978-3-96076-062-7. 